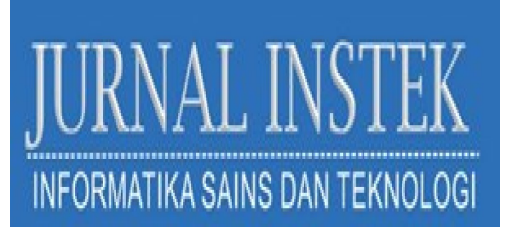

Volume 5 Nomor. 1, April 2020

P-ISSN : 2541-1179, E-ISSN : 2581-1711

Ojs :http://journal.uin-alauddin.ac.id/index.php/instek/index

Email : instek@uin-alauddin.ac.id

\title{
OPTIMALISASI KEANDALAN SISTEM PROTEKSI FEEDER DENGAN RELAY PENUTUP BALIK (AUTO RECLOSER) PADA GARDU INDUK TELLO
}

\author{
AMIRUDDIN $^{1}$, MUHAMMAD HASYIM $^{2}$ \\ Jurusan Teknik Elektro ${ }^{1}$, Jurusan Teknik Mesin ${ }^{2}$ \\ Fakultas Teknik \& Informatika, Universitas Patria Artha \\ Jalan Tun Abdul Razak Kode Pos 92113 \\ Email : amiruddin@patria-artha.ac.id는. muh.hasyim@,patria-artha.ac.id ${ }^{2}$
}

\begin{abstract}
ABSTRAK
Seiring sejalan dengan pertumbuhan ekonomi dan jumlah penduduk, kebutuhan energi listrik semakin besar pula. Apalagi dengan pesatnya pertumbuhan industri dan semakin beragamnya peralatan konsumen yang menggunakan tenaga listrik. Semakin berkembang sistem tenaga listrik dapat mengakibatkan lemahnya performansi system peralatan tenaga listrik ketika mengalami gangguan. Objek penelitian ini adalah bekerjanya relay penutup balik (auto recloser) tiga fasa diakibatkan oleh gangguan pada gardu induk di PLN Sektor Tello dalam jangka periode Juni 2018 - Mei 2019. Adapuncara atau teknik analisis data yang digunakan dalam penelitian ini ialah teknik analisis deskriptif, yaitu mendeskripsikan data dengan memanfaatkan table jumlah gangguan dan lama waktu gangguan guna memutuskan keandalan sistem proteksi feeder relay penutup balik (auto recloser). Total daya yang tidak tersalur diakibatkan oleh gangguan pada feeder yang tidak memakai auto recloser yaitu 58 kali gangguan dengan jumlah waktu pemutusan atau pemadaman $0,94 \mathrm{jam}$. rata-rata beban feeder yang tidak menggunkan auto recloser adalah 63 Ampere, sedangkan jumlah daya yang tidak tersalur karena akibat gangguan pada feeder yang menggunakan auto recloser yaitu 146 kali gangguan dengan jumlah waktu pemadaman 2,45 jam
\end{abstract}

Kata Kunci: Analisis. relay penutup balik. Kehandalan

\section{I.PENDAHULUAN:}

Sejalan dengan pertumbuhan ekonomi dan jumlah penduduk, kebutuhan akan energi listrik semakin besar pula. Apalagi dengan pesatnya pertumbuhan industri dan semakin beragamnya peralatan yang digunakan oleh konsumen yang menggunakan tenaga listrik. Semakin berkembang sistem tenaga listrik dapat berakibat pada tingkat performansi system peralatan tenaga listrik saat mengalami gangguan. Dalam hal ini ada beberapa jenis gangguan yang dapat mengakibatkan gagalnya penyaluran listrik ke konsumen, yakni gangguan sistem dan gangguan non sistem. Penelitian ini bertujuan untuk mengetahui tentang keandalan sistem proteki feeder dengan cara 


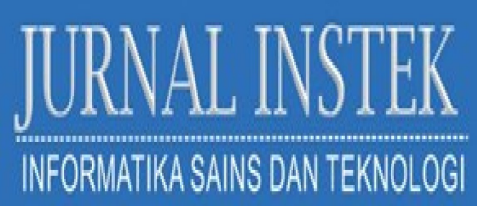

Volume 5 Nomor. 1, April 2020

P-ISSN : 2541-1179, E-ISSN : 2581-1711

Ojs :http://journal.uin-alauddin.ac.id/index.php/instek/index

Email : instek@uin-alauddin.ac.id

membandingkan, antara feeder yang menggunakan auto recloser dengan tidak menggunakan auto recloser. Objek penelitian ini yaitu bekerjanya relay penutup balik (auto recloser) tiga fasa akibat gangguan pada gardu induk di PLN Sektor Tello selama dalam periode tertentu. Adapun teknik analisis data yang digunakan dalam penelitian ini adalah teknik analisis deskriptif, yaitu untuk mendeskripsikan data dengan menggunakan table jumlah gangguan dan lama waktu gangguan untuk menentukan keandalan sistem proteksi feeder relay penutup balik (auto recloser). Proteksi yang tepat, harus dapat bekerja cukup cepat, selektif dan andal sehingga busur gangguan atau pada bagian sistem /peralatan yang dilalalui arus gangguan yang bisa kerusakan peralatan yang mungkin timbul dapat dihindari dan kestabilan sistem dapat terjaga. Sebaliknya jika proteksi gagal bekerja atau terlalu lambat bekerja, maka arus gangguan ini berlangsung lebih lama, sehingga panas yang ditimbulkannya dapat mengakibatkan kebakaran yang hebat, kerusakan yang parah pada peralatan instalasi dan ketidak stabilan sistem. Tangki trafo daya yang menggelembung atau mengalami jebol karena gangguan biasanya diakibatkan karena mengalami kegagalan kerja atau kelambatan kerja proteksi. Kegagalan atau kelambatan kerja proteksi akan mengakibatkan bekerjanya proteksi lain disebelah hulunya (sebagai remote back up) sehingga nantinya dapat mengakibatkan pemadaman yang lebih meluas atau bahkan mampu menyebabkan runtuhnya sistem (collapse).

\section{II.METODE PENELITIAN}

Penelitian keandalan sistem proteksi feeder dengan relay penutup balik (auto recloser) pada GI PLN Sektor Tello, maka variable penelitiannya adalah bekerjanya relay penutup balik (auto recloser) akibat gangguan yang terjadi pada GI PLN Sektor Tello.

Bekerjanya relay penutup balik (auto recloser) akibat adanya gangguan pada GI yang terdiri dari sub variable yaitu:

1. Jumlah gangguan yang terjadi pada feeder-feeder GI.

2. Lama waktu gangguan pada feeder-feeder GI. 
Volume 5 Nomor. 1, April 2020

P -ISSN : 2541-1179, E-ISSN : 2581-1711

Ojs :http://journal.uin-alauddin.ac.id/index.php/instek/index

INFORMATKA SANS DAN TEKNOLOGI

Email : instek@uin-alauddin.ac.id

3. Jumlah daya yang tidak tersalur akibat gangguan yang terjadi pada feederfeeder GI.

Teknik pengumpulan data yang digunakan dalam penelitian ini adalah sebagai berikut:

a) Dokumentasi, yaitu cara yang digunakan untuk mengumpulkan data dengan mengadakan pencatatan data yang dibutuhkan dari berbagai sumber resmi, yaitu data tentang gangguan yang terjadi dan lama waktu gangguan pada feeder-feeder GI PLN sector tello.

b) Observasi, yaitu pengumpulan data dan pencatatan secara langsung terhadap objek penelitian, yaitu tentang banyaknya feeder-feeder serta relay yang terpasang pada GI PLN Sektor Tello.

c) Wawancara, yaitu suatu cara yang ditempuh untuk mengumpulkan data atau informasi langsung, yaitu data tentang kelebihan feeder-feeder yang dilengkapi dengan relay auto recloser dibanding dengan feeder yang tidak dilengkapi dengan relay auto recloser.

Data yang digambarkan dalam penelitian ini antara lain sebagai berikut:

Deskripsi data pada gangguan feeder ini memberikan gambaran tentang hasil penelitian untuk jumlah gangguan feeder-feeder Gardu Induk. untuk feeder tanpa auto recloser dan feeder dengan auto recloser adalah:

a. Feeder tanpa auto recloser, jumlah gangguan yang terjadi (PMT trip) sebanyak

b. Feeder dengan auto recloser, jumlah gangguan yang terjadi terjadi (PMT trip)

c. Jumlah Waktu Pemadaman akibat Gangguan

Untuk mendapatkan gambaran tentang keandalan sistem proteksi feeder dimana waktu pemadaman sebagai objek penelitian yang diolah menurut analisis deskriptif dengan menghitung total waktu dari jumlah gangguan yang terjadi 


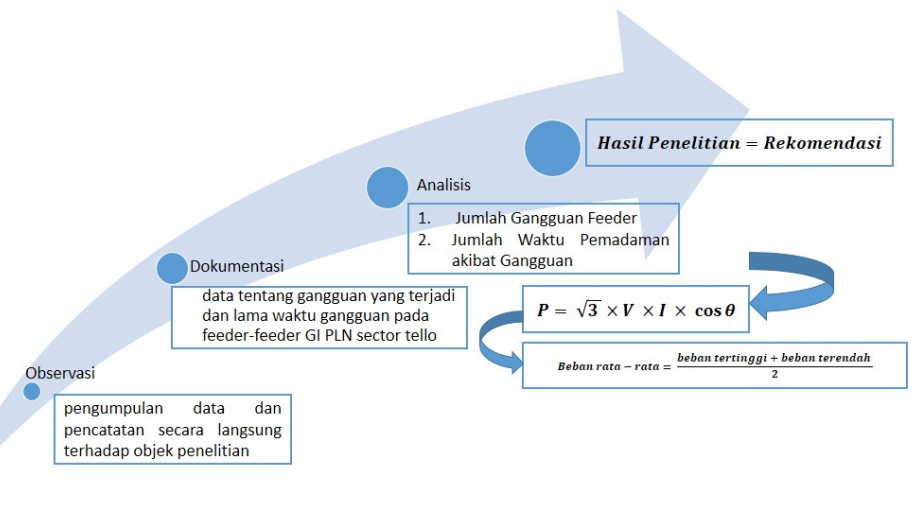

Gambar 1. Alur Penelitian

\section{III.HASIL PENELITIAN}

\section{A. Hasil}

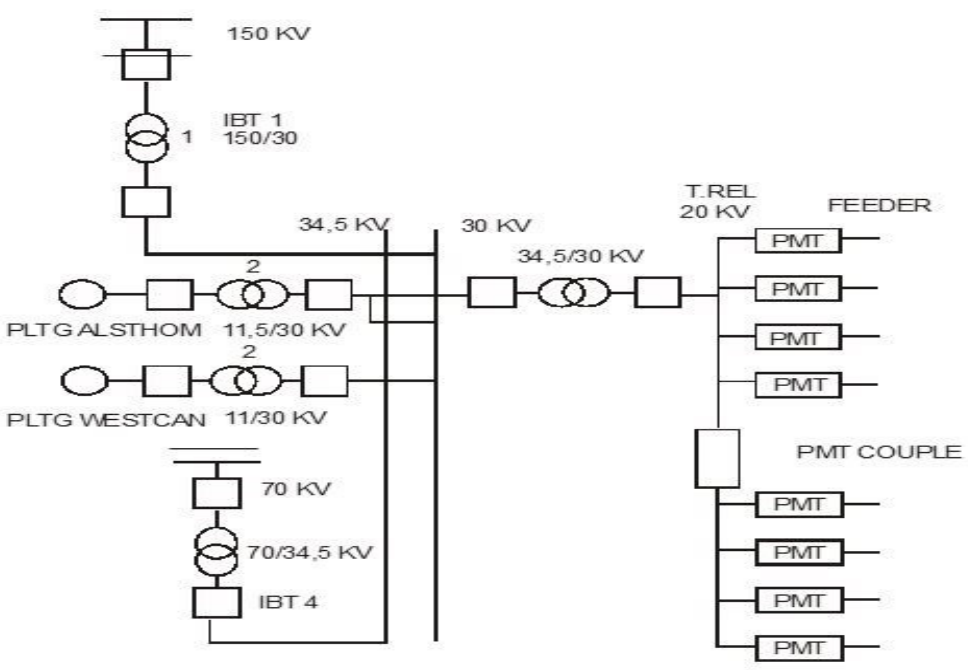

Diagram satu garis gardu induk Tello.

Gambar 2. Diagram Satu Garis Induk Tello 


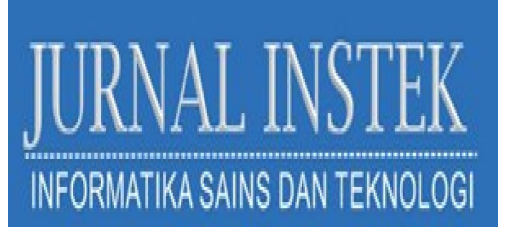

Volume 5 Nomor. 1, April 2020

P -ISSN : 2541-1179, E-ISSN : 2581-1711

Ojs :http://journal.uin-alauddin.ac.id/index.php/instek/index

Email : instek@uin-alauddin.ac.id

Berdasarkan analisa data di atas, memberikan gambaran bahwa jumlah gangguan yang terjadi pada feeder-feeder Gardu Induk sebagian besar atau rata-rata gangguan over current, dan selama kurun waktu Juni 2018 sampai Mei 2019 gangguan under frekuensi tidak ditemukan. Gangguan yang paling sering terjadi adalah gangguan over current dengan fasa terhubung ke tanah dan indikasi yang muncul direlay adalah over current relay ground. Berdasarkan perhitungan tersebut, dalam hasil penelitian juga memberikan gambaran bahwa jumlah gangguan yang terjadi disetiap feeder yang memunculkan pada feeder Bukit Baruga adalah feeder yang paling sering mengalami gangguan. Hal ini disebabkan karena beban feeder Bukit Baruga adalah yang paling tinggi dibandingkan dengan feeder-feeder lainnya. Disamping itu, feeder Bukit Baruga juga mempunyai Jaringan Udara Tegangan Menengah (JUTM) yang paling panjang dibandingkan dengan feeder-feeder yang lain.

JUTM yang panjang sangat memungkinkan terjadi gangguan beban feeder melebihi kemampuan kapasitasnya, juga gangguan yang diakibatkan oleh sambaran pohon disepanjang JUTM. Dan gangguan yang paling banyak dengan indikasi Over Current Relay Ground (OCR-Ground) adalah akibat sambaran ranting pohon atau ranting pohon menyangkut pada JUTM.

Feeder yang paling minim gangguannya adalah feeder Paropo. Hal ini disebabkan karena feeder Paropo melalui JUTM yang sangat dekat dari PLTU Tello dan kondisi alam yang dilalui oleh JUTM sebagian besar adalah perumahan yang kurang pepohonan. Sedangkan feeder PAM sudah tergabung dengan feeder Kodam. Dari perhitungan jumlah waktu pemadaman akibat gangguan, jumlah gangguan yang terjadi pada feeder dengan auto recloser lebih banyak dibandingkan dengan feeder yang tidak dilengkapi dengan auto recloser. Hal ini disebabkan karena proses pemulihan sistem atau proses masuknya PMT pada feeder dengan relay auto recloser dibutuhkan waktu hanya 10 detik pada recloser pertama (I) dan 40 detik pada recloser kedua (II). Sedangkan waktu pemulihan pada feeder yang tidak dilengkapi dengan auto recloser rata-rata dibutuhkan waktu sekitar 60 detik tiap kali trip. Hal ini disebabkan karena yang memasukkan PMT jika trip adalah Gardu Induk. 


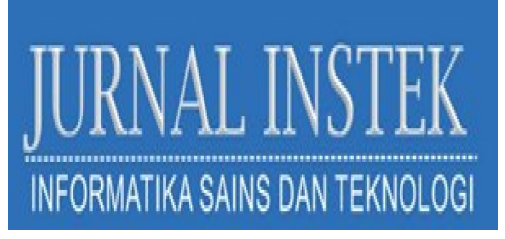

Volume 5 Nomor. 1, April 2020

P-ISSN : 2541-1179, E-ISSN : 2581-1711

Ojs :http://journal.uin-alauddin.ac.id/index.php/instek/index

Email : instek@uin-alauddin.ac.id

Berdasarkan perhitungan jumlah waktu pemadaman akibat gangguan dapat pula dihitung jumlah daya yang tidak tersalur akibat gangguan tersebut. Jumlah daya yang tidak tersalur berbanding lurus dengan jumlah pemadaman artinya semakin lama sistem itu padam maka semakin besar pula daya yang tidak tersalurkan ke konsumen. Dengan asumsi ini jumlah waktu pemadaman dan jumlah daya yang tidak tersalur kita tinjau dari dua sisi yang berbeda:

a) Bagi pihak pelanggan

Berdasarkan misi PLN sebagai pelayan masyarakat maka sasaran utamanya adalah kepuasan pelanggan. Kepuasan pelanggan ditentukan oleh tersalurnya energi listrik dan tersedianya energi listrik ketika pelanggan membutuhkan. Ini berarti PLN mempunyai misi meminimalkan gangguan listrik di rumah-rumah konsumen, atau unit yang membutuhkan energi listrik. Salah satu cara meminimalkan jumlah waktu pemadaman akibat gangguan pada feeder-feeder agar supaya kebutuhan pelaggan terpenuhi adalah dengan memasang auto recloser disetiap feeder secara bertahap.

b) Bagi pihak PLN

Setelah mengusahakan kepuasan dan meminimalkan waktu terputusnya aliran listrik ke pelanggan. Ini tentu mempunyai keuntungan tersendiri bagi PLN. Meminimalkan waktu akibat pemadaman ini berarti meminimalkan daya yang tidak tersalur ke pelanggan. Tidak tersalurnya energi listrik ke konsumen sebagai pelanggan mengakibatkan biaya operasional tinggi sementara pemasukan mengalami penurunan. Semakin lama waktu pemadaman semakin lama pula daya yang tidak teraslur, sementara daya listrik yang dibangkitkan oleh PLN relative tetap atau konstan.

\section{B.Pembahasan}

\section{a. Perhitungan Daya Rata-rata pada Tiap-tiap Feeder}

Perhitungan jumlah daya rata-rata pada tiap feeder dihitung berdasarkan rumus: 
Volume 5 Nomor. 1, April 2020

P-ISSN : 2541-1179, E-ISSN : 2581-1711

Ojs :http://journal.uin-alauddin.ac.id/index.php/instek/index

Email : instek@uin-alauddin.ac.id

$$
P=\sqrt{3} \times V \times I \times \cos \theta
$$

Dimana:

$$
\begin{array}{ll}
\mathrm{P} & : \text { Daya dala satuan (Watt/Jam) } \\
\mathrm{V} & : \text { Tegangan (Volt) } \\
\mathrm{I} & : \text { Arus (Ampere) } \\
\cos \theta & : 0,8
\end{array}
$$

Untuk perhitungan arus dengan beban yang bervariasi, maka yang diambil adalah beban rata-rata yaitu:

$$
\text { Beban rata }- \text { rata }=\frac{\text { beban tertinggi }+ \text { beban terendah }}{2}
$$

Dan untuk tegangan kerjanya diambil 20.000 volt.

Jadi, jumlah daya yang tidak tersalur karena gangguan pada feeder yang tidak menggunakan auto recloser yaitu 57 kali gangguan dengan jumlah waktu pemadaman 0,95 jam. Dan beban rata-rata feeder yang tidak menggunkan auto recloser (feeder Kodam) adalah 63 Ampere. Maka daya yang tidak tersalur:

$$
\begin{aligned}
& =\sqrt{3} \times V \times I \times \cos \theta \\
& =\sqrt{3} \times 20.000 \times 63 \times 0,8 \\
& =1745907,2 \mathrm{Watt} / \mathrm{Jam} \\
& =1745,9072 \mathrm{KW} / \mathrm{Jam} \\
& =1745,9072 \times 0,95=1658,6118 \mathrm{KW}
\end{aligned}
$$

Sedangkan jumlah daya yang tidak tersalur karena gangguan pada feeder yang menggunakan auto recloser yaitu 146 kali gangguan dengan jumlah waktu pemadaman 2,43 jam. Dan beban rata-rata feeder yang menggunkan auto recloser (feeder Bukit Baruga, Unhas Baru, Tamalanrea dan Paropo) adalah :

$$
\begin{aligned}
\text { Beban Rata }- \text { rata } & =\frac{92,5+62,5+59+25}{4}=\frac{239}{4} \\
& =59,75 \text { Ampere }
\end{aligned}
$$


Volume 5 Nomor. 1, April 2020

P -ISSN : 2541-1179, E-ISSN : 2581-1711

Ojs :http://journal.uin-alauddin.ac.id/index.php/instek/index

INFORMATIKASAINS DAN TEKNOLOGI

Email : instek@uin-alauddin.ac.id

Maka daya yang tidak tersalur:

$$
\begin{aligned}
& =\sqrt{3} \times V \times I \times \cos \theta \\
& =\sqrt{3} \times 20.000 \times 59,75 \times 0,8 \\
& =1655840,5 \mathrm{Watt} / \mathrm{Jam} \\
& =1655,8405 \mathrm{KW} / \mathrm{Jam} \\
& =1655,8405 \times 2,43=4023,9241 \mathrm{KW}
\end{aligned}
$$

Jadi, jumlah daya yang tidak tersalur akibat feeder yang menggunakan auto recloser adalah sebanyak 4023,9241 KW.

\section{IV.KESIMPULAN}

Berdasarkan hasil penelitian yang telah di uraikan, maka dapat ditarik kesimpulan sebagai berikut:

1. Total durasi atau lama waktu pemadaman diakibatkan oleh gangguan pada feeder tanpa auto recloser jauh lebih banyak dibanding dengan feeder yang dilengkapi dengan auto recloser, sedang jumlah gangguan yang terjadi justru lebih banyak pada feeder yang menggunakan auto recloser.

2. Jumlah daya yang tidak tersalur dikarenakan gangguan pada feeder yang dilengkapi dengan relay auto recloser lebih sedikit jumlahnya dibandingkan dengan feeder tanpa auto recloser. 


\section{DAFTAR PUSTAKA}

Arikunto, Suharsimi. 2009. Prosuder Penelitian. Rineka Cipta : Jakarta.

Arismunandar, Artono. 2009. Teknik Tegangan Tinggi. Pradyana Paramita : Jakarta.

Dirjen Diknas. 2003. Komponen dan Sistem Proteksi Tenaga Listrik. Depdiknas :Jakarta. Dari proteksi_tenaga_listrik.pdf.

Hadi, Abdul dan Pabla AS. 2009. Sistem Distribusi Daya Listrik. Erlangga : Jakarta.

Poewadarminta, W.J.S. 2009. Kamus Bahasa Indonesia, Cetakan Ke-24. Balai Pustaka : Jakarta.

Mir'atussaada, Adelina (eprints.polsri.ac.id 2015) Evaluasi Cara Kerja Auto Recloser Sebagai Pengaman Pada jaringan Distribusi di PT.PLN (PERSERO) Keramasan.

Pratama, Muhammad Oktavian (eprints.polsri.ac.id 2015) Politeknik Negeri Sriwijaya. Analisa Setting Relay Gangguan Tanah Pada Penyulang 20 Kv Di Gardu Induk Seduduk Putih.

Putra, Ade (repository.umy.ac.id 2017) Studi Analisis Sistem Koordinasi Proteksi Over Current Relay (OCR) dan Ground Fault Relay (GFR) Pada Gardu Induk Godean

Rais M, 2016," Analisis Tegangan Dip Akibat Masuknya Smelter Pada Jaringan Transmisi Dengan Pemodelan Simulasi Komputer", Universitas Patria Artha, http://ejournal.patria-artha.ac.id vol.1 No.1 April 2017 : 55

Insan, Ivan Ahsanul (2017) Optimalisasi Simulasi Maximum Power Point Tracking (Mppt) Pada Solar-Wind Turbine Menggunakan Metode Incremental Conductance. Bachelors degree (s1) thesis, university of muhammadiyah malang.

Hadi Sirat MA, Rais M, Putri AN, Jalal MR, (2018) Optimization of Grounding Resistance to Minimize Transient Current At 150kV Sulselrabar System, IEEE ICOIACT. 